\title{
MANUSCRIPT
}

\section{Design of 3D Multi-Layered Electrospun Membranes Embedding Iron- Based Layered Double Hydroxide for Drug Storage and Control of Sustained Release}

\begin{abstract}
Mariana P. Figueiredo ${ }^{\mathrm{a}, \mathrm{b}, \mathrm{c}}$, Géraldine Layrac ${ }^{\mathrm{b}}$, Anne Hébraud ${ }^{\mathrm{b}}$, Lionel Limousy ${ }^{\mathrm{c}, \mathrm{d}}$, Jocelyne Brendle ${ }^{\mathrm{c}, \mathrm{d}}$, Guy Schlatter ${ }^{\mathrm{b}, *}$, Vera R. L. Constantino ${ }^{\mathrm{a}, *}$
\end{abstract}

${ }^{a} I Q$-USP, Departamento de Química Fundamental, Instituto de Química, Universidade de São Paulo - USP, Av. Prof. Lineu Prestes 748, 05508-000, São Paulo, São Paulo, Brazil.

${ }^{b}$ ICPEES, Institut de Chimie et Procédé pour l'Energie, l'Environnement et la Santé, CNRS UMR 7515, Université de Strasbourg, 25 rue Becquerel, 67087 Strasbourg Cedex 2, France.

${ }^{c}$ Université de Haute-Alsace, IS2M, CNRS UMR 7361, 3b. Rue A. Werner, F68100 Mulhouse, France.

${ }^{d}$ Université de Strasbourg, France.

*corresponding authors: Guy Schlatter, guy.schlatter@unistra.fr; Vera R. L. Constantino, vrlconst@iq.usp.br.

Supplementary information (ESI) available.

Note: the authors declare no competing financial interest. 


\section{ABSTRACT}

Nowadays polymer dressings are expected to possess multiply functions. Besides acting as physical barriers, dressings may provide for the injured tissue species able to turn wound healing process faster and painless. In this way, dressings can be designed aiming to enable the release of drugs. The possibility to modulate drug release kinetics is a desired characteristic to be achieved in order to turn drug delivery systems adequate to specific treatments. However, hydrophilic drugs and hydrophobic polymers incompatibility hinders such modulation and a long-term release cannot be achieved efficiently. Here we present the design of poly(lactic acid) (PLA) membranes containing iron-based Layered Double Hydroxide (LDH) particles able to storage a hydrophilic anionic drug (derived from the non-steroidal anti-inflammatory naproxen). LDH particles are excellent candidates to compose multifunctional composites. They may present diverse biocompatible compositions, possess an elevated encapsulation capacity and tends to promote drugs sustained release by its own, besides assisting tissues regeneration process. Nanofibrous membranes were prepared by the combination of electrospun PLA and electrosprayed LDH as alternated layers (approach A) and also by both technics performed at the same time (approach B). In approach A, by varying the thickness of the PLA fibrous layers, it was possible to easily modulate the drug release rate. Half of drug content was released after 1, 4 and 17 days for the membranes containing the thinnest, the intermediate and the thicker PLA layers, respectively, and after 56 hours for the membrane prepared by the approach B. Naproxen release was kept for 18 days for the thinnest membrane, 59 days for the membrane prepared by the approach B and 66 days for the thicker membranes. We believe that this work can inspire the development of new functional membranes with tunable drug release profile thanks to the versatile electrospinning and electrospraying techniques. 
Keywords: electrospinning; electrospraying; layered double hydroxides; drug release modulation; functional membranes

\section{INTRODUCTION}

The design of composite membranes allowing the precise control of the release kinetics of drugs emerged this last decade for advanced applications in wound dressing, tissue engineering and nanomedicine.[1,2] Especially, in the case of hydrophilic drugs, the controlled delivery over time is an important issue which has to be taken into account in order to deliver the optimal amount of therapeutics to a targeted diseased area while avoiding burst release and undesirable side effects due to overdose. Furthermore, when hydrophilic drugs are embedded in a hydrophobic insoluble polymer membrane, long-term release is more difficult to control due to drug-polymer incompatibility.[3] In this case, partitioning of the drug and the polymer matrix might occur, leading to either burst release or encapsulation of the drug within the matrix. Nanofibrous membranes embedding drugs elaborated from the process of electrospinning have attracted researchers for such applications.[4,5] Indeed, electrospun nanofibrous membranes mimic the extracellular matrix components, enabling cells growth and differentiation. Furthermore, reports have shown that cellfibrous interactions lead to a normal cells phenotypes and gene expression; and fibers possess high surface area/volume ratio and high porosity, which creates nutrient gradients.[6] Among the drug vectors which could be embedded in polymeric membranes, Layered Double Hydroxides (LDHs) have been identified as excellent candidates.[7,8] LDHs are structured bidimensional materials with general formula 
$\left[\mathrm{M}^{2+}{ }_{(1-\mathrm{x})} \mathrm{M}^{3+}{ }_{\mathrm{x}}(\mathrm{OH})_{2}\right]\left(\mathrm{A}^{\mathrm{n}-}\right)_{\mathrm{x} / \mathrm{n}} \bullet \mathrm{zH}_{2} \mathrm{O}$, formed by the stacking of positively charged layers composed by di $\left(\mathrm{M}^{2+}\right)$ and trivalent $\left(\mathrm{M}^{3+}\right)$ metal cations.[9] The $\mathrm{M}^{2+}$ and $\mathrm{M}^{3+}$ ions are distributed in the centre of octahedrons which are formed by six coordinated hydroxide anions, as shown in Figure 1. Structure neutrality is guaranteed by the presence of hydrated anions $\left(\mathrm{A}^{\mathrm{n}-}\right)$ between the layers. These materials are commonly abbreviated by $\mathrm{M}^{2+}{ }_{\mathrm{R}} \mathrm{M}^{3+}-\mathrm{A}^{\mathrm{n}-}$, where $\mathrm{R}$ is the molar ratio between $\mathrm{M}^{2+}$ and $\mathrm{M}^{3+}$. LDH matrix by its own is commercialized as the antacid TALCID ${ }^{\mathrm{TM}}$, composed of magnesium and aluminium cations and intercalated with carbonate anions.[10] Thanks to the biocompatibility of LDHs compositions (verified in vitro and in vivo [11-17]), their effective interactions with biological membranes, high encapsulation efficiency, and capacity to prolong drug release, these materials are promising to be applied as vehicles for drug storage and delivery.[18-20] In this way, many species such as aminoacids,[21] anti-inflammatories [22] and cancer drugs [23] have been intercalated between the LDHs layers. Recently our group showed that LDHs may interfere positively in tissue regeneration, being able to conduct the formation of different types of collagen according with the layer composition.[16,17] Furthermore, the combination of the LDH matrix with polymers has been used to prepare mimetic bone substituents, conferring mechanical strength and remodeling facilities by stress shielding.[24,25] The release of species such as healing cells activator from LDHs layers has improved even more bone regeneration process.[26]

Therefore, electrospun membranes embedding LDHs may form interesting implantable functional composites with drug release properties, acting as supports for damaged tissues due to surgery interferences and improving tissues regeneration. To the best of our knowledge, the only approach proposed in the literature consists in dispersing LDHs in the polymer solution which is further electrospun leading 
consequently to a membrane in which $\mathrm{LDH}$ nanoparticles are inside the matrix of fibers.[27] Besides, in this case, LDHs compositions presented only $\mathrm{Al}^{3+}$ as trivalent cations, an exogenous metal. Valarezo et al.[27] reported the release of amoxicillin preencapsulated into the $\mathrm{LDH}$ layers of composition $\mathrm{Zn}_{2} \mathrm{Al}$, itself encapsulated into poly $(\varepsilon$ polycaprolactone) (PCL) fibers. While homogeneous fibers were obtained for LDH content of $3 \% \mathrm{wt}$, the formation of beads was observed for a higher LDH content of 5 and $7 \% \mathrm{wt}$, showing the limitation of the possible amount to be loaded in the polymer composites. The slowest drug release rate was observed for the membrane presenting 3 $\%$ wt of LDH amoxicillin, extending for more than 20 days. Other works reported the intercalation of non-steroidal anti-inflammatory drugs into LDHs of composition $\mathrm{Mg}_{2} \mathrm{Al}$ or $\mathrm{Mg}_{3} \mathrm{Al}$. Yang et al.[28] applied flurbiprofen acetyl as model drug, poly(lactic-coglycolic acid) (PLGA) as polymeric matrix and $5 \%$ of LDH-drug concentration relative to the polymer. Heterogeneous fibers diameter due to the presence of beads were observed for the LDH-PLGA nanofibers. After 5 days, less than $40 \%$ of the drug was released. The work of Tammaro et al.[29] showed that PCL fibers containing $\mathrm{Mg}_{3} \mathrm{Al}$ LDHs intercalated with diclofenac anions also exhibited a slow release of the drug (50 $\%$ after 240 days). Gao et al.[30] reported the intercalation of ibuprofen or ketoprofen into the $\mathrm{LDH}$ of composition $\mathrm{Mg}_{2} \mathrm{Al}$ and composites formed with PCL polymer. It was verified that fibers diameter tends to increase when the LDH amount in the composite increases. After 5 days, 44 and $48 \%$ of ibuprofen were released from composite membranes containing 5 and $10 \%$ wt of $\mathrm{LDH}$, respectively. However, for the same period of time and same LDH content, only 25 and $20 \%$ of ketoprofen were released. Miao et al.[31] also reported the pre-encapsulation of anions derived from ibuprofen into the $\mathrm{Mg}_{2} \mathrm{Al} \mathrm{LDH}$ for preparation of composites based on poly(lactic acid) (PLA) and PCL electrospun fibers containing $5 \%$ wt of LDH. Despite the hydrophobicity of both 
polymers, ibuprofen release from PCL was faster than from PLA fibers: approximately $40 \%$ and less than $10 \%$ after $2 \mathrm{~h}$, respectively. This behavior was attributed to the poor chain flexibility of PLA. Although a slow release is desired most of the time in medicine's formulation, it is interesting to find mechanisms to modulate the drug release rate from the carrier, in order to adjust the formulation according with the treatment of different diseases, with different bioactive species and administration routes. Examples of a desired faster drug release include the administration of extra dose insulin during meals[32,33] and anti-inflammatories to immediate relief of low or moderate pain.[34] On the other hand, a sustained drug release is intended when longterm drug circulation and treatments are necessary, such as in the administration of basal doses insulin unrelated to meals [33,35] and postoperative antibiotics,[36] anaesthetics[37] and anti-inflammatories,[34] to avoid infections and severe chronic pains. In this way, the same work presented a strategy in order to increase and modulate the hydrophilicity of the PLA fibers based on the addition of poly(oxyethylene-boxypropylene-b-oxyethylene) (Pluronic) into the processed formulation, leading to a faster drug release. 


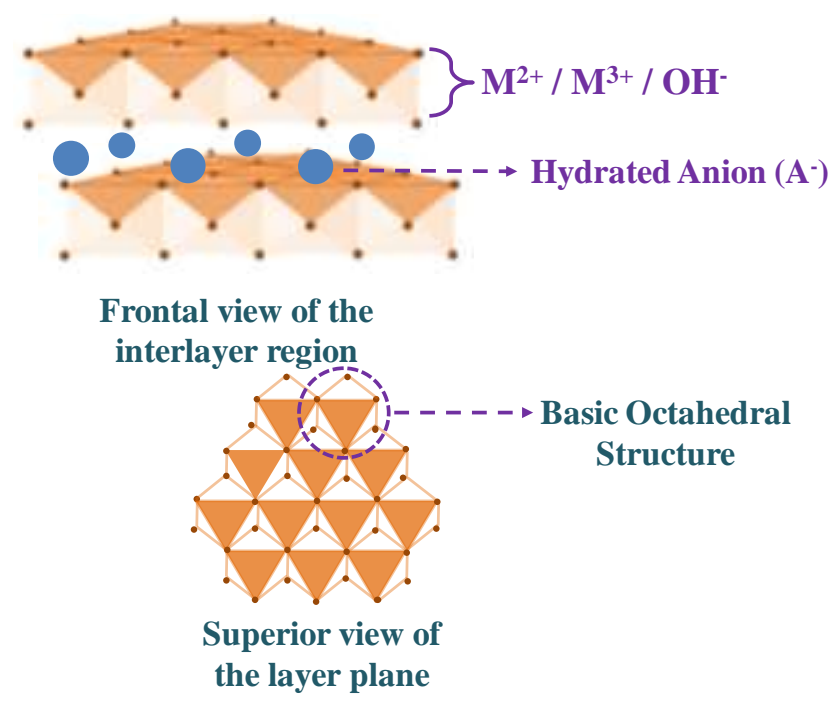

Figure 1. Schematic representation of the LDH structure.

The studies above mentioned showed that the LDH concentration in the polymer solution is limiting, since its increase tends to the formation of beads and, consequently, non-homogeneous fibers. Furthermore, hydrophobicity of most biocompatible polymers such as PLA, PLGA and PCL, which can be easily processed by electrospinning, hinders drug release in aqueous media.[38] Therefore, the development of strategies in order to overcome the polymers hydrophobicity and modulate drug release rates is desirable to expand the possible administration routes of electrospun membranes.

The present work is inspired by our previous results for which composite scaffolds elaborated from the combination of electrospinning and electrospraying processes show interesting properties due to the presence of both nanofibers and microparticles components. For example, when electrosprayed particles are simultaneously or alternately deposited with electrospun fibers, scaffolds with various patterns can be obtained.[39,40] Hybrid scaffolds with PCL fibers and hydroxyapatite particles can also be envisaged for bone regeneration application.[41] Furthermore, it was also demonstrated that scaffolds entrapping hydrophilic particles in a hydrophobic 
fibrous mesh allow the modulation of the hydrophilicity/hydrophobicity balance. Such property was exploited to fabricate fibrous membranes allowing the controlled release of a drug.[42]

Here, two kinds of membranes having different structures and made of PLA electrospun nanofibers and drug-loaded-LDH electrosprayed microparticles were elaborated in order to modulate the kinetic of drug release while avoiding the use of any hydrophilic adjuvant. Multilayer membranes with LDH particles in sandwich between PLA fibrous layers of various thicknesses were studied and compared with membranes in which the LDH particles were entrapped in the fibrous PLA mesh. PLA was chosen as polymer due to its biocompatibility, good mechanical properties and performance for fibers formation. Aluminum accumulation has been verified in different tissues and has being associated to neurodegenerative diseases.[43-45] Therefore, in order to turn the drug delivery devices more promising for biological applications, half of the $\mathrm{Al}^{3+}$ content was substituted by $\mathrm{Fe}^{3+}$ cations (endogenous) in the LDHs composition. Naproxenate was applied as a model hydrophilic drug and was pre-encapsulated into LDHs layers. In order to compare the effect of the organic anions regarding the interaction between LDHs particles and fibers, similar membranes were prepared with LDH precursors intercalated with $\mathrm{Cl}^{-}$anions.

\section{Experimental section}

Poly(D,L-lactide) (PLA) (MW 180 kDa, L = 95\%, NatureWorks 7000D). N,Ndimethylformamide $(\geq 99.8 \%)$, dichloromethane $(\geq 99.8 \%)$, magnesium chloride hexahydrate $\left(\mathrm{MgCl}_{2} \cdot 6 \mathrm{H}_{2} \mathrm{O}\right)(99 \%)$, aluminum chloride hexahydrate $\left(\mathrm{AlCl}_{3} \cdot 6 \mathrm{H}_{2} \mathrm{O}\right)(99$ $\%)$, iron(III) chloride hexahydrate $\left(\mathrm{FeCl}_{3} \cdot 6 \mathrm{H}_{2} \mathrm{O}\right)(98 \%)$, sodium chloride $(\mathrm{NaCl})(99.5$ 
$\%)$, sodium hydroxide $(\mathrm{NaOH})$ and sodium naproxenate (NaNAP) $\left(\mathrm{NaC}_{14} \mathrm{H}_{13} \mathrm{O}_{3}\right)$ with purity $\geq 98 \%$, were purchased from Sigma-Aldrich. Ethanol absolute was purchased from Carlo Erba. All products were used as received.

\subsection{LDH preparation}

LDHs, intercalated with NAP and $\mathrm{Cl}^{-}$anions, were prepared following the procedure previously reported,[17] with some changes and adapted as follows.

\subsubsection{Synthesis of the $\mathrm{Mg}_{4} \mathrm{FeAl}-\mathrm{Cl}$ sample}

The $\mathrm{LDH}$ intercalated with $\mathrm{Cl}^{-}$anions, abbreviated by $\mathrm{Mg}_{4} \mathrm{FeAl}-\mathrm{Cl} \mathrm{LDH}$, was prepared under $\mathrm{N}_{2}$ atmosphere by the co-precipitation method at constant $\mathrm{pH}$ equal to 10.5 , by adding under mechanical stirring at $900 \mathrm{rpm}$ and $50^{\circ} \mathrm{C}$ concomitantly a mixture of a $0.05 \mathrm{~mol} \cdot \mathrm{L}^{-1}$ solution of $\mathrm{MgCl}_{2} \cdot 6 \mathrm{H}_{2} \mathrm{O}, \mathrm{FeCl}_{3} \cdot 6 \mathrm{H}_{2} \mathrm{O}$ and $\mathrm{AlCl}_{3} \cdot 6 \mathrm{H}_{2} \mathrm{O}$ (to obtain a $\mathrm{Fe}^{3+} / \mathrm{Al}^{3+}$ molar ratio equal to 1) and a $0.2 \mathrm{~mol} \mathrm{~L}^{-1} \mathrm{NaOH}$ solution into $200 \mathrm{~mL}$ deionized water. After addition, the mixture was aged under stirring for $1 \mathrm{~h}$ at the same synthesis temperature. The obtained solid was recovered by filtration, washed with $2 \mathrm{~L}$ of deionized water and lyophilized for $24 \mathrm{~h}$ at $200 \mathrm{mbar}$ and $-50^{\circ} \mathrm{C}$ (in a Thermo Savant ModulyoD equipment). The $\mathrm{Mg}_{4} \mathrm{FeAl}-\mathrm{Cl} \mathrm{LDHs}$ used to test the stability of the particles suspension were prepared by a similar procedure, with exception of the mechanical stirring rate, kept at $400 \mathrm{rpm}$.

\subsubsection{Intercalation of $\mathrm{NAP}$ into the $\mathrm{Mg}_{4} \mathrm{FeAl} \mathrm{LDH}$ by ion exchange method}

Starting from the remaining slurry of the $\mathrm{Mg}_{4} \mathrm{FeAl}-\mathrm{Cl} \mathrm{LDH}$ synthesis, not submitted to washing procedure, the excess of $\mathrm{Cl}^{-}$ions was removed by centrifugation with 4 cycles of $3 \mathrm{~min}$ each at $10000 \mathrm{rpm}$. For the preparation of approximately $0.5 \mathrm{~g}$ of 
the $\mathrm{LDH}$ intercalated with NAP, abbreviated by $\mathrm{Mg}_{4} \mathrm{Fe} A \mathrm{Al}-\mathrm{NAP}$, the precursor was resuspended in $20 \mathrm{~mL}$ of an aqueous solution of NaNAP in a molar ratio NAP / $\left(\mathrm{Fe}^{3+}+\right.$ $\mathrm{Al}^{3+}$ ) equal to 3 . The suspension was kept under $\mathrm{N}_{2}$ atmosphere and vigorously stirring with stir bar at $200 \mathrm{rpm}$ for $24 \mathrm{~h}$ at $80{ }^{\circ} \mathrm{C}$. The solid was washed with deionized water by filtration under reduced pressure and then dried by freeze drying in the same conditions applied for the $\mathrm{Mg}_{4} \mathrm{FeAl}-\mathrm{Cl} \mathrm{LDH}$.

\subsection{Preparation of suspensions and solution}

\subsubsection{Preparation of LDH suspension to be electrosprayed}

The LDH suspension used to prepare the LDH-PLA membranes has been optimized for efficient electrospraying of the smallest aggregates (see Supporting Information and figures S1-S3). LDHs-ethanol suspensions (1\% wt) were previously submitted to ultrasonication (Branson Digital Sonifier equipment) at $40 \%$ amplitude for 30 min ( 2 seconds on / 2 seconds off) just before the electrospraying procedure.

\subsubsection{Preparation of PLA solution to be electrospun}

A $10 \%$ wt PLA solution was prepared by dissolving the beads in a mixture of dichloromethane and dimethylformamide in weight ratio equal to $3: 2$ overnight under slow stirring with a magnetic stirring bar.

\subsection{Preparation of the composite membranes}

Two approaches are proposed for the preparation of composite membranes. The approach A consists in the fabrication of multi-layered membranes by alternating electrospinning PLA fibers and electrospraying LDHs particles. In approach B, LDHs 
electrosprayed particles are regularly dispersed in the PLA electrospun fibrous membrane.
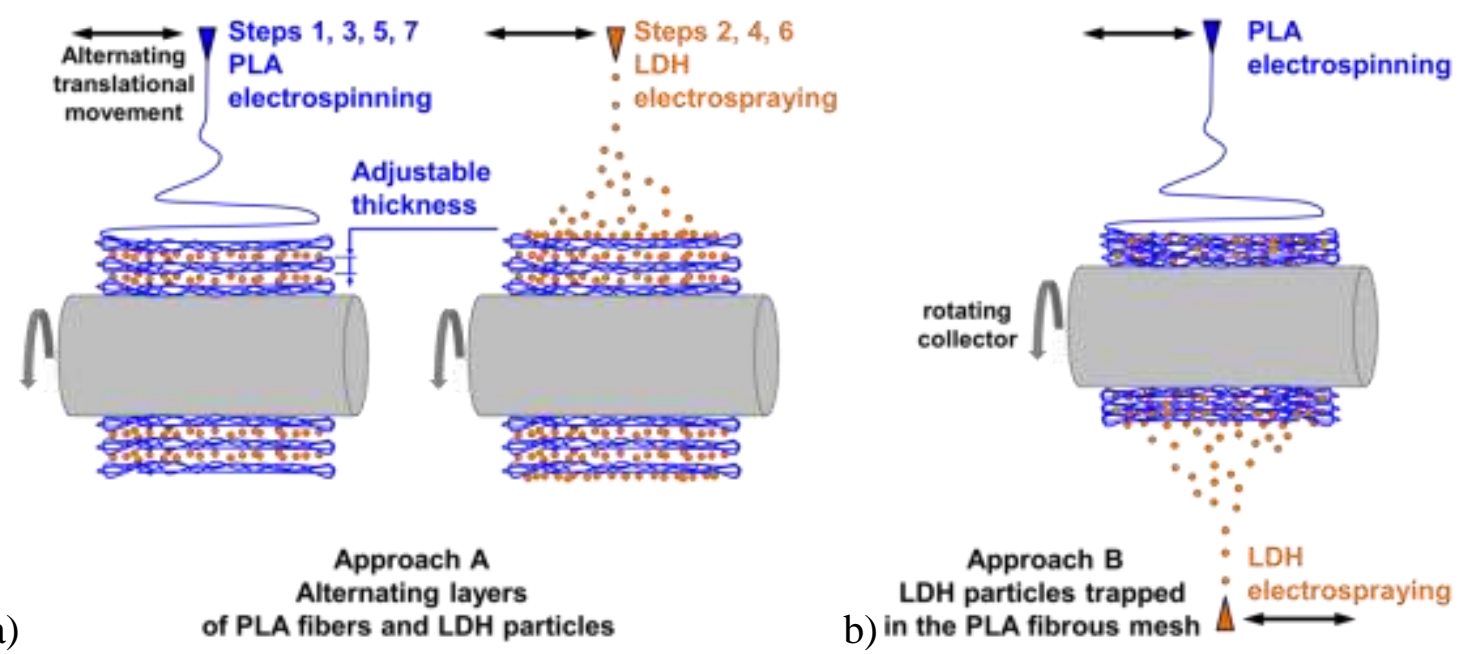

Figure 2. Preparation of the composite membranes in the case of a) approach A with variable and adjustable thickness of the PLA fibrous layers and b) approach B with simultaneous PLA electrospinning and LDH electrospraying.

\subsubsection{Electrospun PLA and electrosprayed LDH: building up a delivery membrane (Approach A)}

Electrospinning and electrospraying experiments were conducted with a homemade setup previously described [42] and allowing the deposition on a drum collector rotating at $125 \mathrm{rpm}$. All solutions or suspensions were electrospun or electrosprayed at a temperature $\mathrm{T}=22+/-1^{\circ} \mathrm{C}$ and a relative humidity $\mathrm{RH}=40+/-5 \%$. Working distance between needle and collector was equal to $16 \mathrm{~cm}$ for all samples. For all electrospinning and electrospraying steps, an alternating translation movement (see Figure 2, amplitude of the movement $=7 \mathrm{~cm}$, average velocity of the movement $=2 \mathrm{~cm} / \mathrm{s}$ ) of the needle was imposed in order to enlarge the deposition leading to the fabrication of membranes having a width of $11 \mathrm{~cm}$. 
In approach $\mathrm{A}$, the membranes contain 7 layers made from the deposition of 4 PLA electrospun fibers taking in sandwich 3 LDHs electrosprayed particles (Figure 2a). Three different PLA layer thicknesses were prepared by changing the production time of the electrospun layers. Applied voltages, flow rates and production times are given in Table 1. Membranes containing electrosprayed $\mathrm{Mg}_{4} \mathrm{Fe} A \mathrm{Al}$-NAP particles are called NAP-A thin, NAP-A $A_{\text {med }}$, NAP- $A_{\text {thick }}$ and the membranes with electrosprayed $\mathrm{Mg}_{4} \mathrm{Fe} \mathrm{Al}-\mathrm{Cl}$ are called $\mathrm{Cl}-\mathrm{A}_{\text {thin }}, \mathrm{Cl}-\mathrm{A}_{\text {med }}, \mathrm{Cl}-\mathrm{A}_{\text {thick}}$. In order to compare the samples, the total electrospraying time was the same for each membrane and equal to 78 minutes.

Table 1. Applied parameters for preparation of the membranes

\begin{tabular}{|c|c|c|c|c|c|}
\hline Approach & Method & $\begin{array}{l}\text { Voltage on } \\
\text { the needle } \\
\qquad(\mathrm{kV})\end{array}$ & $\begin{array}{l}\text { Voltage on } \\
\text { the collector } \\
(\mathrm{kV})\end{array}$ & $\begin{array}{c}\text { Flow rates } \\
\left(\mathbf{m L} \cdot \mathbf{h}^{-1}\right)\end{array}$ & $\begin{array}{c}\text { Production } \\
\text { Time } \\
\text { (min) }\end{array}$ \\
\hline $\mathrm{A}_{\text {thin }}, \mathrm{A}_{\text {med }}$ & Electrospraying & 25 & 0 & 6 & 3 layers \\
\hline $\mathrm{A}_{\text {thick }}$ & Layers 2, 4, 6 & & & & $26 \mathrm{~min} / \mathrm{layer}$ \\
\hline \multirow{2}{*}{$\mathrm{A}_{\text {thin }}$} & Electrospinning & 16 & -5 & 2.8 & 4 layers \\
\hline & Layers $1,3,5,7$ & & & & $15 \mathrm{~min} / \mathrm{layer}$ \\
\hline \multirow{2}{*}{$\mathrm{A}_{\text {med }}$} & Electrospinning & 16 & -5 & 2.8 & 4 layers \\
\hline & Layers $1,3,5,7$ & & & & $22 \mathrm{~min} /$ layer \\
\hline \multirow{2}{*}{$\mathrm{A}_{\text {thick }}$} & Electrospinning & 16 & -5 & 2.8 & 4 layers \\
\hline & Layers $1,3,5,7$ & & & & $30 \mathrm{~min} / \mathrm{layer}$ \\
\hline \multirow{2}{*}{ B } & Electrospinning & 16 & & 2.8 & \\
\hline & Electrospraying & 28 & 0 & 6 & $78 \mathrm{~min}$ \\
\hline
\end{tabular}




\subsubsection{Simultaneous PLA electrospinning and LDH electrospraying}

(Approach B)

In approach B (Figure 2b, Table 1), the membranes were prepared by simultaneous deposition of electrospun PLA and electrosprayed LDH aiming to contain the same total amount of LDH as applied in approaches A (total electrospraying time equal to $78 \mathrm{~min}$ ). For both needles an alternating translation movement (amplitude of the movement $=7 \mathrm{~cm}$, average velocity of the movement $=2 \mathrm{~cm} / \mathrm{s}$ ) was imposed in order to enlarge the deposition and allowing thus the fabrication of membranes having a width of $11 \mathrm{~cm}$. Samples were abbreviated as $\mathrm{Cl}-\mathrm{B}$ and NAP-B, indicating the application of $\mathrm{B}$ approach and $\mathrm{LDH}$ particles containing $\mathrm{Cl}^{-}$and NAP anions, respectively.

\subsubsection{Pristine PLA membrane}

As a control, pristine PLA membrane was electrospun for 2 hours. Therefore, it contained the same polymer amount as in the membranes prepared according with approach $\mathrm{A}_{\text {thick}}$.

\subsection{NAP release tests}

Naproxen release experiments were conducted in triplicate from $3 \mathrm{~cm} \mathrm{x} 10 \mathrm{~cm}$ membranes. The membranes were accommodated in closed glass flasks containing 70 $\mathrm{mL}$ of saline aqueous solution $(0.9 \% \mathrm{wt} \mathrm{NaCl})$; the $\mathrm{pH}$ value was equal to $5.55 \pm 0.01$. The release media was magnetically stirred at $130 \mathrm{rpm}$ and the assays were performed in a climatized room at $22{ }^{\circ} \mathrm{C}$. At specified time, $3 \mathrm{~mL}$ of saline solution were collected and replaced with an equivalent amount of dissolution medium. NAP concentration was determined by UV-visible absorption spectrophotometry at a maximum absorption $\left(\lambda_{\max }\right)$ equal to $230 \mathrm{~nm}$. After the first released NAP aliquot measured, accumulative 
NAP weight $\left(\mathrm{m}^{\mathrm{NAP}}{ }_{i}\right)$ released was corrected through the equation (1), where $\mathrm{Ci}$ is the NAP concentration $\left(\mathrm{mL} \mathrm{L}^{-1}\right)$ in such a time $i$, considering the removed aliquots $(3 \mathrm{~mL})$ for measurement in anterior times $k$ and then replaced by the same volume of saline solution in order to maintain the flasks volume equal to $70 \mathrm{~mL}$.

$$
m_{i}^{N A P}=0.07 C_{i}+0.003 \sum_{k=1}^{k=i-1} C_{k}
$$

\subsection{Materials characterization}

X-ray diffraction (XRD) patterns of powdered LDHs were obtained on a Bruker D8 Advance A25 equipment with variable slits mode, using $\mathrm{Cu}$ anode $(\lambda=1.518 \AA)$, scan range $1.5-70^{\circ}(2 \theta)$ and scan step of $0.02^{\circ}(2 \theta) / \mathrm{s}$.

Fourier transform infrared (FT-IR) spectra of powdered LDH samples and of the composites were recorded in the $4000-400 \mathrm{~cm}^{-1}$ range on a Bruker spectrophotometer, model $\alpha$, by attenuation total reflection (ATR) mode with acquisition step of $4 \mathrm{~cm}^{-1}$ and 512 scans.

Fourier transform Raman (FT-Raman) spectra of the LDH samples were recorded in an FTRaman Bruker FRS-100/S spectrometer using 1064 nm exciting radiation (Nd:YAG laser Coherent Compass 1064-500 N), a Ge detector, laser power of 100 $\mathrm{mW}$, acquisition step of $4 \mathrm{~cm}^{-1}$, and 2048 scans.

Chemical elemental analyses of carbon, hydrogen, and nitrogen were recorded on Perkin Elmer-CHN 2400.

Inductively coupled plasma atomic emission spectroscopy (ICP-AES) analyses of metals were performed in duplicate on Spectro Analytical Instrument.

Images by scanning electron microscopy (SEM) of the membranes were obtained in a VEGA3SEM equipment using samples deposited on a copper tape and coated with 
gold using a Q150RS Quorum equipment. The LDHs micrographs were obtained in a XL30 FEG Philips equipment depositing the powders in a copper tape and covering samples with carbon.

Mechanical tensile measurements were performed with a TA Instruments Discovery HR-3 hybrid rheometer at room temperature and applying a velocity of $50 \mu \mathrm{m} \mathrm{s}^{-1}$. The normal force sensor of the rheometer was used to record the tensile force. Samples were analysed in quintuplicate and were prepared cutting $3 \times 1.5 \mathrm{~cm}$ rectangles. The mechanical tests were carried out at room temperature $\left(\mathrm{T}=21 \pm 2^{\circ} \mathrm{C}\right)$ and humidity $(\mathrm{RH}$ $=50 \pm 20 \%$ ) without environmental control.

Thermogravimetric analysis (TGA) data were recorded on TA instrument, Q5000 model, using platinum crucible and a heating rate of $10{ }^{\circ} \mathrm{C} \min ^{-1}$, from room temperature to $1000{ }^{\circ} \mathrm{C}$, under synthetic air flow of $25 \mathrm{~mL} \mathrm{~min}^{-1}$.

Membranes thicknesses were determined using a Schut digital micrometre. Six measurements in different points were performed in samples with $3 \mathrm{~cm} \times 10 \mathrm{~cm}$ area.

Contact angle measurements were performed with static deionized water drop on the membranes using a DSA 25 tensiometer.

Absorbance in the ultraviolet-visible spectral region was measured on a Shimadzu UV-2600 spectrometer. 


\section{Results and discussion}

\section{1. $\mathrm{Mg}_{4} \mathrm{FeAl}-\mathrm{Cl}$ and $\mathrm{Mg}_{4} \mathrm{FeAl}-\mathrm{NAP} \mathrm{LDHs}$ characterization}

LDH samples intercalated with $\mathrm{Cl}^{-}$anions or NAP were first fully characterized. Figure S4 (Supplementary Information) presents the XRD patterns of $\mathrm{Mg}_{4} \mathrm{Fe} \mathrm{Al}-\mathrm{Cl}$ (precursor) and $\mathrm{Mg}_{4} \mathrm{FeAl}-\mathrm{NAP}$ samples. Precursor $\mathrm{LDH}$ diffractogram displays the characteristics peaks (narrow and well resolved) related to the LDH phase.[9] On both diffractograms peaks are narrow revealing a structural organization. After NAP intercalation, the shift of the (001) peaks to small angles region is observed, which indicates that the interplanar distances are higher, endorsing the organic anion intercalation. Moreover many (001) harmonic peaks are visualized for the hybrid LDH. The presence of the residual $\mathrm{Mg}_{4} \mathrm{FelAl}-\mathrm{Cl}$ phase in the $\mathrm{Mg}_{4} \mathrm{FeAl}-\mathrm{NAP}$ sample is evidenced by the permanence of the (113) reflection, normally displaced to small angles region and not visualized for single phases LDHs intercalated with bulky anions, once it is dependent of the c crystallographic parameter. Mixture of phases is commonly observed for NAP intercalation by ion-exchange reaction in MgAl LDHs and also by coprecipitation method.[17,46-48]

FT-IR spectra of the LDH materials are present in Figure S5. The band at 1361 $\mathrm{cm}^{-1}$ is assigned to the antisymmetric stretching of the carbonate anions (contaminant), while the broad bands below $700 \mathrm{~cm}^{-1}$ are assigned to the metal-OH translation.[9] For the $\mathrm{Mg}_{4} \mathrm{FeAl}-\mathrm{NAP}$ sample, the band at $1230 \mathrm{~cm}^{-1}$ is attributed to the in plane bending of the $\mathrm{C}-\mathrm{H}$ bounds in the naphthalene ring. The bands at 1392 and $1545 \mathrm{~cm}^{-1}$ can be assigned to the stretching modes of the $\mathrm{COO}^{-}$group.[46]

FT-Raman spectra of the LDHs are presented in Figure S6. For the precursor phase, the less intense band at $1062 \mathrm{~cm}^{-1}$ is assigned to the symmetric stretching of 
adsorbed carbonate anions.[49] The band at $540 \mathrm{~cm}^{-1}$ is assigned to metal-OH translation modes. For the $\mathrm{Mg}_{4} \mathrm{FeAl}-\mathrm{NAP}$ sample, the most intense bands at 1632 and $1416 \mathrm{~cm}^{-1}$ are attributed to $\mathrm{C}-\mathrm{C}$ ring vibrations while the band at $1386 \mathrm{~cm}^{-1}$ is assigned to $\mathrm{CH}_{3}$ deformation.[17]

TGA curves of the $\mathrm{Mg}_{4} \mathrm{FeAl}-\mathrm{Cl}$ and $\mathrm{Mg}_{4} \mathrm{FeAl}-\mathrm{NAP}$ materials are shown in Figures S7 and S8, respectively. Three and four main mass loss events are observed, for the precursor and the hybrid LDH sample, respectively. For both compounds, the first and second events, occurring from room temperature up to $180{ }^{\circ} \mathrm{C}$ and $230{ }^{\circ} \mathrm{C}$ for the precursor LDH and for the hybrid material, respectively, are associated to the release of adsorbed and intercalated water molecules. For the $\mathrm{Mg}_{4} \mathrm{Fe} \mathrm{Al}-\mathrm{Cl}$ sample, the third event, that occurs between $180-600{ }^{\circ} \mathrm{C}$, is assigned to the matrix dehydroxylation. The residual mass corresponds to $59.5 \%$ wt. For the $\mathrm{Mg}_{4} \mathrm{FeAl}-\mathrm{NAP} \mathrm{LDH}$, the third and fourth mass loss events correspond to the overlapping matrix dehydroxylation and NAP decomposition. The smaller residual mass (46.4\% wt) observed, in comparison with the precursor material, agrees with NAP presence.

SEM micrographs of the $\mathrm{Mg}_{4} \mathrm{FeAl}-\mathrm{Cl}$ and $\mathrm{Mg}_{4} \mathrm{Fe} A l-N A P$ samples are present in Figure S9. For both samples, a sand rose morphology and many sets of 2D plates are visualized. The great similarity between the sample's morphology suggests that the chloride-exchange is a topotactic process, in which the final lattice is determined by the lattice of the pristine $\mathrm{LDH}$.

The elemental chemical composition of the $\mathrm{Mg}_{4} \mathrm{FelAl}-\mathrm{Cl}$ and $\mathrm{Mg}_{4} \mathrm{FeAl}-\mathrm{NAP}$ LDHs, as well as the amount of water obtained by TGA experiments, are gathered in Table 2. Molar ratio between the metals are close to the nominal values. Naproxen anions were intercalated in appreciable amounts (36.17 $\mathrm{g}$ of NAP for $100 \mathrm{~g}$ of hybrid). 
Table 2. Elemental chemical composition of $\mathrm{Mg}_{4} \mathrm{FeAl}-\mathrm{Cl}$ and $\mathrm{Mg}_{4} \mathrm{Fe} A l-\mathrm{NAP}$ LDHs.

\begin{tabular}{|c|c|c|c|c|c|c|c|}
\hline Sample & $\mathbf{M g} / \mathrm{Al}$ & $\mathrm{Mg} / \mathrm{Fe}$ & $\mathrm{Fe} / \mathrm{Al}$ & $\begin{array}{c}\mathrm{Mg} / \\
(\mathrm{Fe}+\mathrm{Al})\end{array}$ & $\% \mathrm{H}_{2} \mathrm{O}$ & wt \% C & wt $\%$ NAP \\
\hline $\mathrm{Mg}_{4} \mathrm{FeAl}-\mathrm{Cl}$ & 4.32 & 4.08 & 1.06 & 2.10 & 13.0 & ----- & ----- \\
\hline $\mathrm{Mg}_{4} \mathrm{FeAl}-\mathrm{NAP}$ & 4.36 & 4.18 & 1.04 & 2.14 & 14.4 & 26.51 & 36.17 \\
\hline
\end{tabular}

\subsection{D Composite membranes by PLA electrospinning and LDH electrospraying}

Membranes micrographs are presented in Figure 3. Regarding the multi-layered membranes obtained from approach A, some LDH particles are exposed on the surface of the membranes containing the thinnest PLA layers $\left(\mathrm{Cl}-\mathrm{A}_{\text {thin }}\right.$ and NAP- $\left.\mathrm{A}_{\text {thin }}\right)$. Increasing the PLA thickness, fewer particles are visualized on $\mathrm{Cl}-\mathrm{A}_{\text {med }}$ and $\mathrm{NAP}-\mathrm{A}_{\text {med }}$ surfaces and no particles are observed for the $\mathrm{Cl}-\mathrm{A}_{\text {thick }}$ and NAP- $\mathrm{A}_{\text {thick }}$ samples. The surface aspects of the $\mathrm{Cl}-\mathrm{A}_{\text {thick }}$ and NAP- $\mathrm{A}_{\text {thick }}$ samples are similar to the one of the pristine PLA membrane, indicating that $30 \mathrm{~min}$ of PLA electrospinning is enough to completely cover the last layers containing LDHs particles. Less particles aggregation is observed for the membranes prepared from approach $B$ by simultaneous PLA electrospinning and LDH electrospraying (Cl-B and NAP-B samples) compared to the particles distribution on surface of the thinnest membranes and to the surfaces aspect of the last deposited LDH layers (L), abbreviated by $\mathrm{Cl}-\mathrm{A}_{\text {thick }} \mathrm{L}$ and NAP- $\mathrm{A}_{\text {thick }} \mathrm{L}$ samples. Indeed, in the approach A, a large number of particles is electrosprayed at the same time, favoring the formation of aggregates on the mat, as was seen when electrospraying on a flat collector (Figure S1 in SI) whereas in approach B, only few particles are electrosprayed before new fibers land on the mat and hide them, hindering the formation of aggregates. 


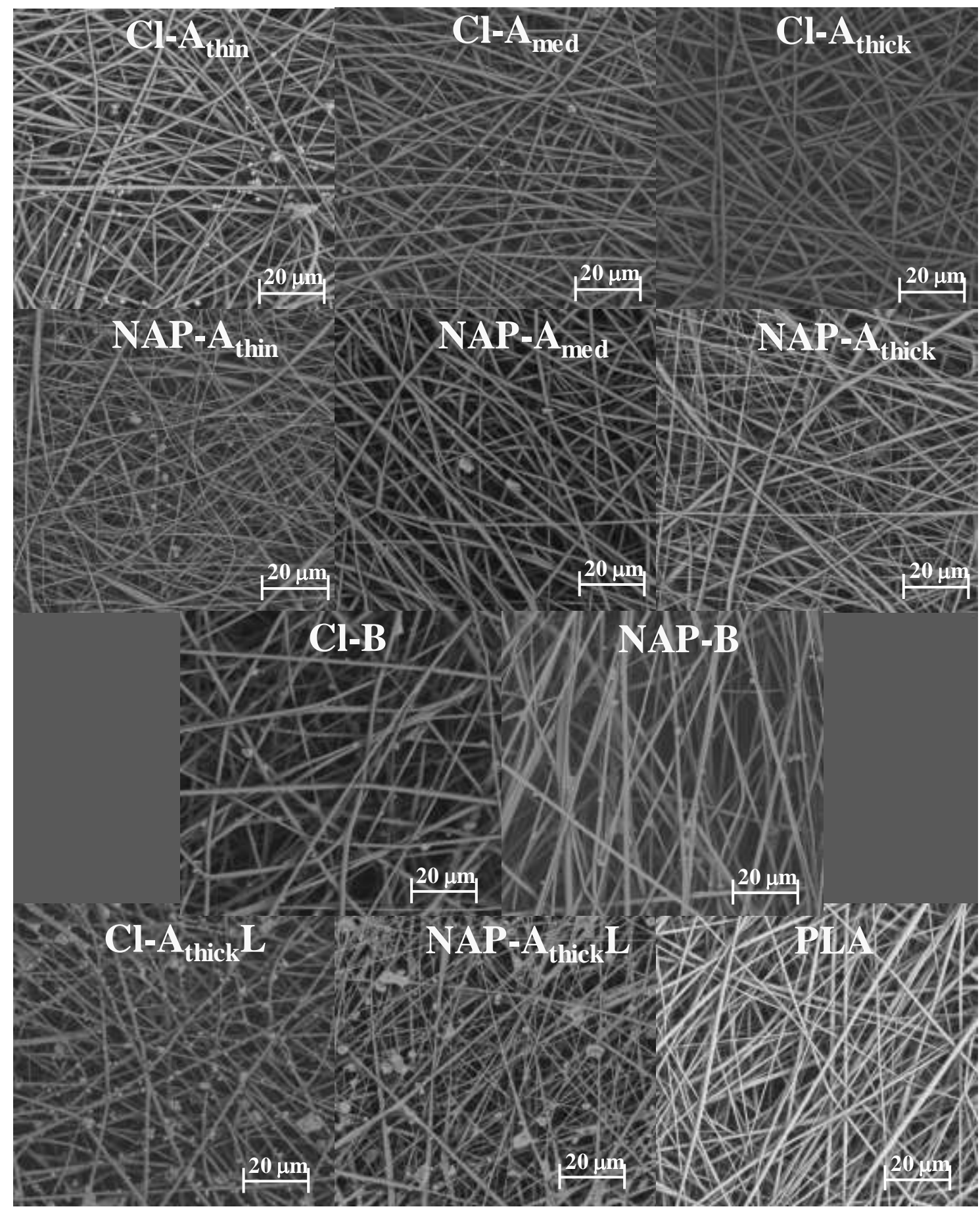

Figure 3. SEM micrographs of pristine PLA membrane and PLA membranes containing $\mathrm{Mg}_{4} \mathrm{FeAl} \mathrm{LDHs}$ intercalated with $\mathrm{Cl}^{-}$and NAP anions, prepared by alternating 4 electrospun PLA layers with 3 electrosprayed LDH layers (Approach A) with different PLA thickness $\left(\mathrm{A}_{\text {thin }}-\right.$ electrospinning of each layer performed for 15 min, $A_{\text {med }}-22$ min and $A_{\text {thick }}-30 \mathrm{~min}$ ) and prepared by both electrospinning and electrospraying at the same time (Approach B). Samples were analyzed applying BSE detector, $5 \mathrm{kV}$ and work distance around $10 \mathrm{~mm}$. 
FT-IR spectra of the membranes containing Cl-LDH (Figure 4a) and NAP-LDH (Figure 4b) particles have been obtained. All bands observed for the pristine PLA (Figure S10) are present in the spectra related to the composites, whose assignment was made as follows.[50] The bands at 2994 and $2945 \mathrm{~cm}^{-1}$ are attributed to the antisymmetric and symmetric stretching of the $-\mathrm{CH}_{3}$ group, respectively. The band at $1751 \mathrm{~cm}^{-1}$ is assigned to the stretching of the $-\mathrm{C}=\mathrm{O}$ group. Antisymmetric $-\mathrm{CH}_{3}$ bending frequency is observed at $1452 \mathrm{~cm}^{-1}$, while the corresponding symmetrical mode appears at $1361 \mathrm{~cm}^{-1}$. The bands at $1261,1184,1129,1084$ and $1043 \mathrm{~cm}^{-1}$ are related to vibrational modes of the C-O-C group. Finally, the band at $867 \mathrm{~cm}^{-1}$ is related to the stretching of the $\mathrm{O}-\mathrm{CH}-\mathrm{CH}_{3}$ portion and the band at $753 \mathrm{~cm}^{-1}$ to the wagging of the $\alpha$ $\mathrm{CH}_{3}$ group. For the membranes whose SEM images show higher levels of exposed particles, the bands at $3430 \mathrm{~cm}^{-1}$, in the spectra for $\mathrm{Cl}-\mathrm{A}_{\text {thick }} \mathrm{L}$ and $\mathrm{Cl}-\mathrm{B}$, and at $3433 \mathrm{~cm}^{-}$ ${ }^{1}$, for the NAP-A $\mathrm{A}_{\text {thick }} \mathrm{L}$ and NAP-B samples, respectively, are attributed to the stretching of the $-\mathrm{OH}$ group presented in the LDH layers and to intercalated and adsorbed water molecules. Bands below $700 \mathrm{~cm}^{-1}$, attributed to the metal-OH stretching, are also present in the spectra of the $A_{\text {thick }} L$ and $B$ samples. Additionally, for the NAP- $A_{\text {thick }} L$ sample, the bands at 1547,926 and $473 \mathrm{~cm}^{-1}$ are assigned to vibration modes of NAP anions.[17] 

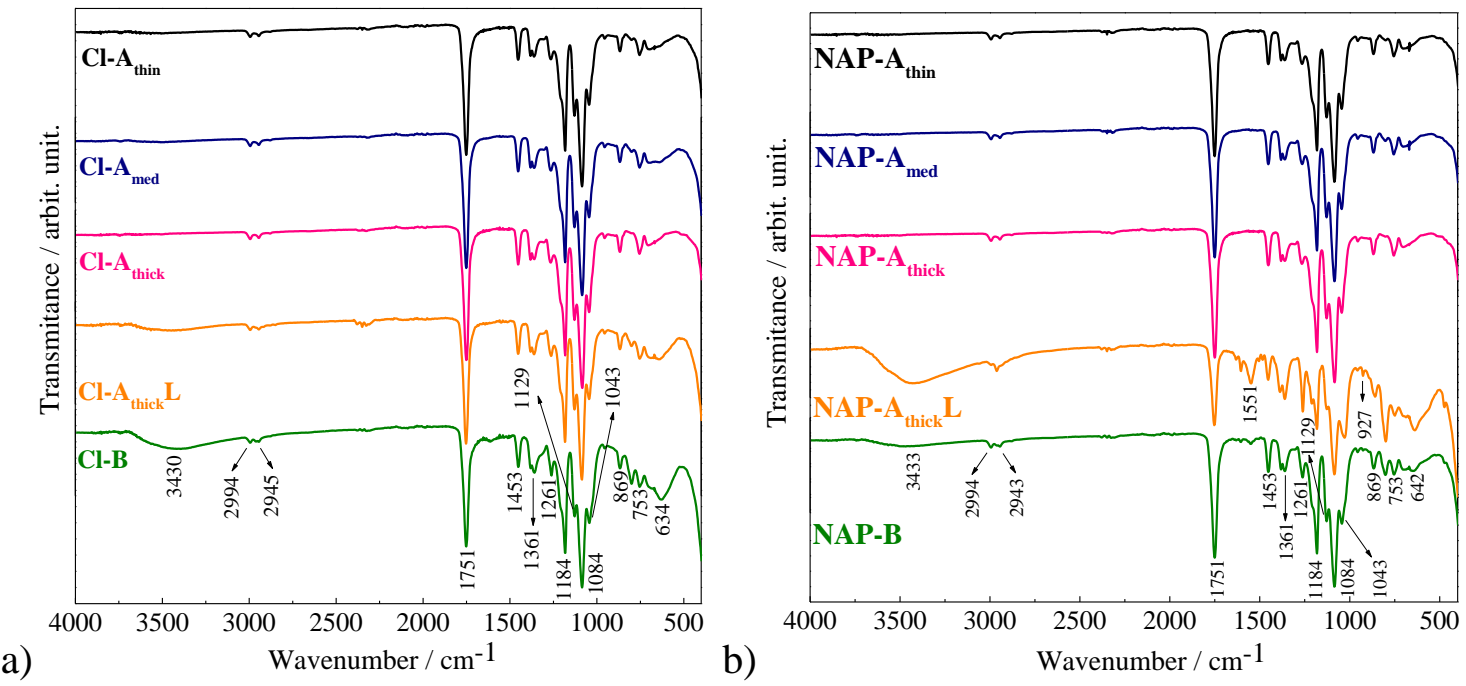

Figure 4. FT-IR spectra of membranes containing a) Cl-LDHs particles and b) NAPLDH particles.

Table 3 presents the membranes thickness. A non-significant difference was observed for the membranes prepared by the same approach, differing by the presence of $\mathrm{Cl}-\mathrm{LDH}$ or NAP-LDH particles, indicating a similarity in particles distribution during electrospraying method, independent of the nature of the LDH. In agreement with the architecture of the membranes, according with the consecutive increase in PLA layers thickness from $A_{\text {thin }}$ to $A_{\text {thick }}$, it was observed the corresponding increase in thickness, from $61 \pm 24 \mu \mathrm{m}$ for $\mathrm{Cl}-\mathrm{A}_{\text {thin }}$ and $53 \pm 21 \mu \mathrm{m}$ for $\mathrm{NAP}-\mathrm{A}_{\text {thin }}$ to $116 \pm 14 \mu \mathrm{m}$ for $\mathrm{Cl}-\mathrm{A}_{\text {thick }}$ and $120 \pm 16 \mu \mathrm{m}$ for $\mathrm{NAP}-\mathrm{A}_{\text {thick}}$, respectively. Comparing the membranes prepared by B approach (78 min of PLA deposition) with the ones prepared by $\mathrm{A}_{\text {med }}$ approach, in which the PLA fibbers content is slightly higher (88 min of PLA deposition as compared to 78 min for $\mathrm{B}$ ), a decrease in thickness is observed for $\mathrm{Cl}-\mathrm{B}$ and NAP-B samples. It may indicate a better particles-PLA fibers accommodation when electrospinning and electrospraying are performed at the same time.

Static water contact angles (SCA) for the pristine PLA and LDH-PLA membranes, as well as for the last LDH elestrosprayed layer of the $\mathrm{A}_{\text {thick }}$ samples $(\mathrm{Cl}-$ 
$\mathrm{A}_{\text {thick }} \mathrm{L}$ and NAP- $\mathrm{A}_{\text {thick }} \mathrm{L}$ ) are compiled in Table 3 (see also Figure S11). Comparing the SCA value of the pristine electrospun PLA $\left(129^{\circ} \pm 5^{\circ}\right)$ with the values for the ClLDH-PLA samples, it is observed a decrease in the hydrophobicity to $124^{\circ} \pm 6^{\circ}$ for the $\mathrm{Cl}-\mathrm{A}_{\text {thick }}$ sample and a more pronounced decrease for the other Cl-LDH-PLA samples. When NAP-LDH particles are present in the composites, the decrease in hydrophobicity compared to the pristine electrospun PLA membrane is less pronounced, showing the property of NAP anions in conferring higher hydrophobicity to the LDHs.

Table 3. Membranes average thickness, static water contact angle and mechanical properties obtained by tensile tests for PLA membrane and PLA_LDH composites.

\begin{tabular}{|c|c|c|c|c|c|c|c|}
\hline Sample & $\begin{array}{c}\text { Membranes } \\
\text { Thickness } \\
(\mu \mathrm{m})\end{array}$ & $\begin{array}{c}\text { Contact } \\
\text { Angle } \\
\left(^{\circ}\right)\end{array}$ & $\begin{array}{l}\text { Yield } \\
\text { stress } \\
(\mathrm{MPa})\end{array}$ & $\begin{array}{c}\text { Yield } \\
\text { strain } \\
(\%)\end{array}$ & $\begin{array}{c}\text { Stress at } \\
\text { break } \\
\text { (MPa) }\end{array}$ & $\begin{array}{c}\text { Strain at } \\
\text { break } \\
(\%)\end{array}$ & $\begin{array}{c}\text { Young } \\
\text { modulus } \\
(\mathrm{MPa})\end{array}$ \\
\hline PLA & $148 \pm 22$ & $129 \pm 5$ & $1.9 \pm 0.1$ & $2.9 \pm 0.1$ & $3.1 \pm 0.2$ & $70 \pm 1$ & $98 \pm 5$ \\
\hline $\mathrm{Cl}-\mathrm{A}_{\text {thin }}$ & $61 \pm 24$ & $121 \pm 4$ & $1.5 \pm 0.1$ & $3.3 \pm 0.3$ & $2.1 \pm 0.2$ & $82 \pm 4$ & $74 \pm 6$ \\
\hline $\mathrm{Cl}-\mathrm{A}_{\mathrm{med}}$ & $102 \pm 22$ & $121 \pm 5$ & $1.5 \pm 0.2$ & $2.8 \pm 0.6$ & $2.5 \pm 0.2$ & $82 \pm 6$ & $82 \pm 7$ \\
\hline $\mathrm{Cl}-\mathrm{A}_{\text {thick }}$ & $116 \pm 14$ & $124 \pm 6$ & $2.1 \pm 0.1$ & $3.0 \pm 0.3$ & $3.9 \pm 0.2$ & $100 \pm 3$ & $109 \pm 6$ \\
\hline $\mathrm{Cl}-\mathrm{B}$ & $86 \pm 26$ & $121 \pm 5$ & $1.5 \pm 0.2$ & $2.8 \pm 0.9$ & $2.8 \pm 0.3$ & $79 \pm 6$ & $76 \pm 12$ \\
\hline $\mathrm{Cl}-\mathrm{A}_{\text {thick }} \mathrm{L}$ & -------- & $121 \pm 5$ & -------- & -------- & -------- & -------- & ------- \\
\hline NAP-A $A_{\text {thin }}$ & $53 \pm 21$ & $126 \pm 5$ & $0.7 \pm 0.4$ & $2.6 \pm 0.8$ & $1.4 \pm 0.9$ & $42 \pm 5$ & $39 \pm 28$ \\
\hline NAP-A $A_{\text {med }}$ & $92 \pm 19$ & $127 \pm 5$ & $1.8 \pm 0.1$ & $4.6 \pm 0.5$ & $2.4 \pm 0.1$ & $100 \pm 2$ & $85 \pm 2$ \\
\hline NAP-A $A_{\text {thick }}$ & $120 \pm 16$ & $127 \pm 6$ & $2.0 \pm 0.2$ & $2.7 \pm 0.7$ & $3.6 \pm 0.1$ & $52 \pm 2$ & $96 \pm 5$ \\
\hline NAP-B & $99 \pm 33$ & $125 \pm 5$ & $1.7 \pm 0.1$ & $3.1 \pm 0.1$ & $2.5 \pm 0.1$ & $81 \pm 3$ & $84 \pm 1$ \\
\hline NAP-A $A_{\text {thick }} L$ & -------- & $127 \pm 5$ & -------- & -------- & -------- & ------- & -------- \\
\hline
\end{tabular}

Table 3 presents mechanical properties (Young modulus, yield stress and strain and stress and strain at break) of the membranes obtained by tensile measurements. Stress-strain curves can also be seen in Figure S12. Although LDH-fibers interactions might change the mechanical behaviour, it is shown that the amount of incorporated LDH is not enough to significantly affect the tensile properties. 
Technological medical devices, such as multifunctional dressings, require a deep understanding of the materials structure in order to tune materials properties and explain their behaviour once applied. LDHs were previously fully characterized and a high drug load was verified. Physicochemical properties of the nanofibers membranes were investigated. The interaction degree among PLA nanofibers and LDHs particles responded to the applied approach and resulted in mechanical properties improvements. The different membranes presented a particular superficial morphology, in which modifications in the thickness of the polymeric diffusional barrier are expected to affect the drug release profile, discussed below.

\subsection{Kinetic of NAP release: effect of the membranes morphology}

Drug released amount was calculated from the calibration curve shown in Figure S13. Initial release, highlighted in Figure 5a, shows that after 5 min more than $5 \%$ of NAP was released and probably LDH particles present in the membrane's surface were responsible by the initial burst, with exception of the NAP-A $A_{\text {thick }}$ sample, whose initial drug release was delayed for about 2 hours. Later release profile, better visualized in Figure 5b, shows a considerable release rate difference among the samples. Half of NAP amount was released after 24, 56, 96 and $408 \mathrm{~h}$ (17 days) of experiment for the NAP- $A_{\text {thin }}$, NAP-B, NAP-A $A_{\text {med }}$ and NAP-A $A_{\text {thick }}$ composites, respectively. The release rate can be correlated with the degree of LDH particles exposure to the saline solution media. Besides, in order to reach the LDH particles inside the structure, the aqueous media has to penetrate through the PLA layers, which are hydrophobic. From $A_{\text {thin }}$ to $A_{\text {thick}}$, the thickness of the PLA layer increases, increasing the penetration time inside the membrane and slowing the drug release. Naproxen was released over 18 days for the 
NAP- $A_{\text {thin }}$ sample and for longer time for the other samples: 59 days for the membrane prepared by the approach B and 66 days for both NAP-A $A_{\text {med }}$ and NAP- $\mathrm{A}_{\text {thick}}$, after which it reached a plateau.
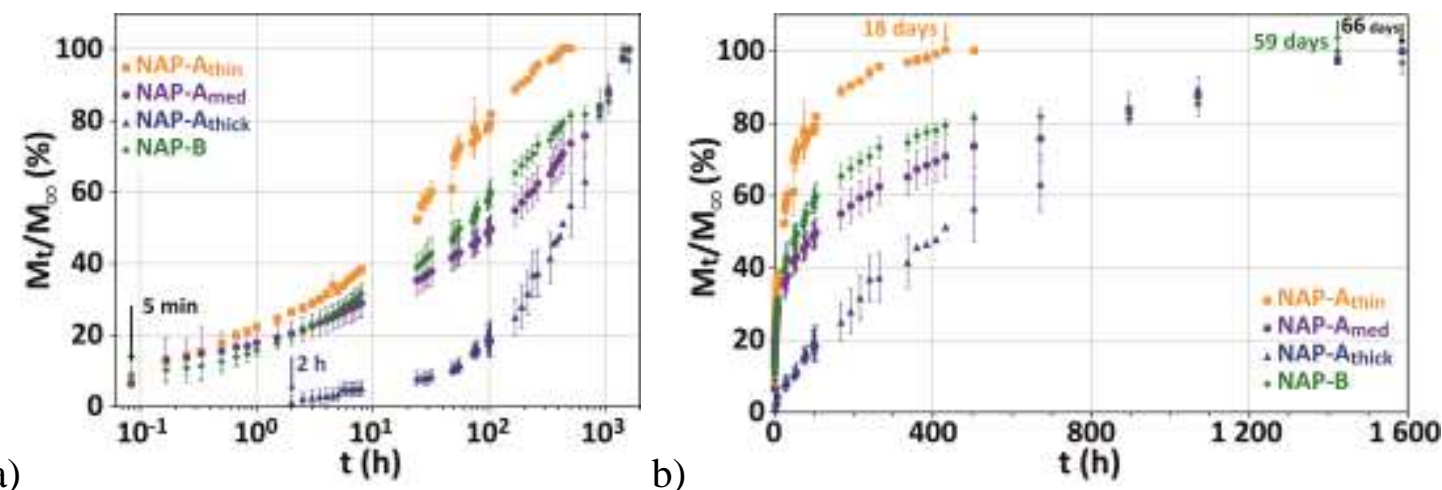

Figure 5. Drug release profile: naproxen release percentage as a function of time for the different composites. a) Semi-log scale. b) Linear scale.

In order to get more insight in the release mechanisms, the naproxen release profiles of the different membranes were fitted by the power law Ritger-Peppas model[51] (equation 2) which is currently used to describe the drug release process from matrices in general and polymeric systems:

$$
\frac{\mathrm{M}_{\mathrm{t}}}{\mathrm{M}_{\infty}}=\mathrm{Kt^{ \textrm {n } }}
$$

Where $\mathrm{M}_{\mathrm{t}}$ is the drug amount released after a time $\mathrm{t}$ and $\mathrm{M}_{\infty}$ is the drug amount at the equilibrium state. Figure 6 presents the curves of the model as well as the obtained kinetic parameters (constant $\mathrm{K}$ and release exponent $\mathrm{n}$ ) and linear correlation coefficients $\left(\mathrm{R}^{2}\right)$. Drug release from all devices was well fitted by the Power Law model, with $\mathrm{R}^{2}$ values greater than 0.98 . The low $\mathrm{n}$ values obtained for NAP- $\mathrm{A}_{\text {thin }}$, NAP-A $A_{\text {med }}$ and NAP-B membranes (respectively $0.28,0.23$ and 0.26 ), smaller than 0.45 , suggests a Fickian type release with dominant diffusion process.[51-53] In the case of $\mathrm{NAP}-\mathrm{A}_{\text {thick }}$ membranes, $\mathrm{n}$ value is larger and equal to 0.59 , characterizing an anomalous 
transport. It must be mentioned that such model gives only an overall behavior of the membrane rendering difficult an exact description of the drug release mechanisms and especially the lag-time observed for the NAP- $\mathrm{A}_{\text {thick }}$ membranes. The release behavior of LDH materials (i.e. no associated to a polymer) is often related to a Fickian diffusion, which is based on ion exchange process. [54,55] However, in our case, the multilayer structure of the membranes induces a complex sequential flow through the PLA nanofibrous layers and then, through the LDH electrosprayed layers. The latter being the domains where the drug is initially released by intra-LDH-particles and inter-LDHparticles diffusion. Considering the architecture of the NAP- $\mathrm{A}_{\text {thick }}$ membranes, it is possible to propose that initially the release medium permeates the pores of the PLA hydrophobic mesh of the external layer. Then, after this first step, exchange of NAP by $\mathrm{Cl}^{-}$saturating the $\mathrm{LDH}$ layers allows the release of the drug through the porous layer of PLA towards the external medium. The drug release delay was not evidenced for all other membranes because some LDH particles were immediately exposed to the release medium as shown in Figure 3 for the membranes containing the thinnest PLA layers (i.e. NAP- $A_{\text {thin }}$, NAP-A $\left.A_{\text {med }}, N A P-B\right)$.

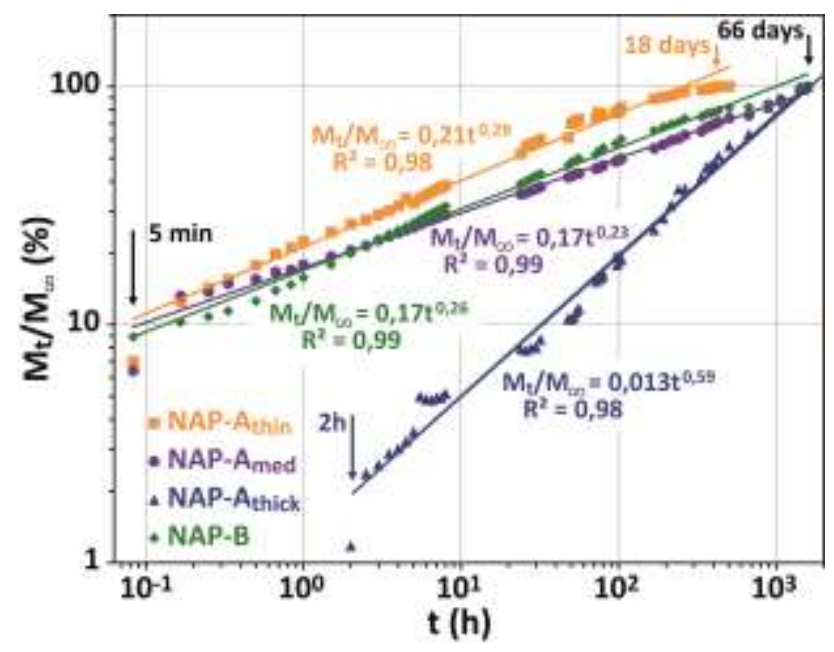

Figure 6. Experimental points and Ritger-Peppas model (solid lines) of Naproxen release percentage as a function of time for the different composites in log-log scale. 
In order to better understand the dissimilarity among the dissolution profiles for the membranes prepared by the different approaches, the "difference factor" $\left(\boldsymbol{f}_{\mathbf{1}}\right)$ and the "similarity factor" $\left(\boldsymbol{f}_{2}\right)$, described by equations $\mathbf{3}$ and $\mathbf{4}$, respectively, were calculated and are indicated by the Agência Nacional de Vigilância Sanitária (The Brazilian Health Regulatory Agency) [56] and by the FDA [57] to compare tested and reference formulations. Where, $N$ is the number of dissolution time points and $\boldsymbol{R} \boldsymbol{t}$ and $\boldsymbol{T t}$ are the dissolution values (percentages in our case) for the reference and the tested system at a time $t$, respectively. The factor values are shown in Table 4. Dissolutions profiles are considered equivalents if $\boldsymbol{f}_{\mathbf{1}}$ is between 0 and 15 and if $\boldsymbol{f}_{\mathbf{2}}$ is between 50 and 100, as observed among the NAP- $\mathrm{A}_{\text {med }}$ and NAP-B membranes, while all other membranes show a different profile, compared two by two.

$$
\begin{aligned}
& f_{1}=100\left(\frac{\sum_{t=1}^{N}\left|R_{t}-T_{t}\right|}{\sum_{t=1}^{N} R_{t}}\right) \\
& f_{2}=50 \log \left[100\left[1+\frac{1}{N} \sum_{t=1}^{N}\left(R_{t}-T_{t}\right)^{2}\right]^{-0.5}\right]
\end{aligned}
$$

Table 4. "Difference" $\left(\boldsymbol{f}_{1}\right)$ and "similarity" $\left(\boldsymbol{f}_{\mathbf{2}}\right)$ factors calculated for the composites compared two by two.

\begin{tabular}{c|ccccc}
\hline $\boldsymbol{R} \boldsymbol{t}$ & $\mathbf{N A P - A _ { \text { thin } }}$ & $\mathbf{N A P - A}_{\text {med }}$ & NAP-B & NAP-B & NAP-B \\
\hline $\boldsymbol{T} \boldsymbol{t}$ & $\mathbf{N A P - A}_{\text {med }}$ & $\mathbf{N A P - A}_{\text {thick }}$ & NAP-A $_{\text {thin }}$ & NAP-A $_{\text {med }}$ & NAP-A $_{\text {thick }}$ \\
\hline $\boldsymbol{f}_{\mathbf{1}}$ & 28.4 & 44.7 & 27.7 & 10.0 & 49.5 \\
\hline $\boldsymbol{f}_{\mathbf{2}}$ & 33.2 & 32.1 & 39.9 & 60.4 & 27.7 \\
\hline
\end{tabular}

\section{Conclusions}

The development of 3D multi-layered electrospun membranes containing drug loaded iron-based LDH particles was achieved with the aim of forming multifunctional 
dressings by different approaches. In approach A, a faster, an intermediate and a slower NAP release were observed for the thin, medium and thick PLA layer thickness, respectively. Therefore, drug release could be modulated by simply varying the preparation parameter. Compared to the membranes prepared by the approach A, approach B involved only one step preparation and the membrane presented an intermediate NAP release profile. The developed membranes fulfilled important characteristics expected for a technological drug delivery device, since the prepared drug delivery composites were able to modulate and keep NAP release for more than two months. Furthermore, membranes architecture can inspire the development of even more interesting and functional devices based on electrospinning and electrospraying techniques.

\section{ACKNOWLEGEMENTS}

This work was supported by Fundação de Amparo à Pesquisa do Estado de São Paulo (Research Internships Abroad, BEPE- FAPESP 2018/22726-7) and Conselho Nacional de Desenvolvimento Cientifico e Tecnológico (CNPq, 305446/2017-7), and is part of the Research Academic Cooperation Agreement PRC CNRS-FAPESP (PRCProjet de recherche Conjoint 1688 and SPRINT-São Paulo Researchers in International Collaboration 2016/50317-9). We are thankful to Céline Piras for the technical support. Laboratório de Espectroscopia Molecular Hans Stammreich (LEM, Instituto de Química-USP) is also acknowledged for the Raman and FT-IR spectra recording. 


\section{REFERENCES}

[1] S. Merino, C. Martín, K. Kostarelos, M. Prato, E. Vázquez, Nanocomposite Hydrogels: 3D Polymer-Nanoparticle Synergies for On-Demand Drug Delivery, ACS Nano. 9 (2015) 46864697. https://doi.org/10.1021/acsnano.5b01433.

[2] D. Mertz, S. Harlepp, J. Goetz, D. Bégin, G. Schlatter, S. Bégin-Colin, A. Hébraud, Nanocomposite Polymer Scaffolds Responding under External Stimuli for Drug Delivery and Tissue Engineering Applications, Advanced Therapeutics. n/a (2019) 1900143. https://doi.org/10.1002/adtp.201900143.

[3] S.-F. Chou, D. Carson, K.A. Woodrow, Current strategies for sustaining drug release from electrospun nanofibers, J Control Release. 220 (2015) 584-591. https://doi.org/10.1016/j.jconrel.2015.09.008.

[4] H. Cheng, X. Yang, X. Che, M. Yang, G. Zhai, Biomedical application and controlled drug release of electrospun fibrous materials, Materials Science and Engineering: C. 90 (2018) 750763. https://doi.org/10.1016/j.msec.2018.05.007.

[5] Y. Sun, S. Cheng, W. Lu, Y. Wang, P. Zhang, Q. Yao, Electrospun fibers and their application in drug controlled release, biological dressings, tissue repair, and enzyme immobilization, RSC Advances. 9 (2019) 25712-25729. https://doi.org/10.1039/C9RA05012D.

[6] N. Bhardwaj, S.C. Kundu, Electrospinning: A fascinating fiber fabrication technique, Biotechnology Advances. 28 (2010) 325-347.

https://doi.org/10.1016/j.biotechadv.2010.01.004.

[7] Poly(L-lactic acid) nanocomposites with layered double hydroxides functionalized with ibuprofen - Dagnon - 2009 - Journal of Applied Polymer Science - Wiley Online Library, (n.d.). https://onlinelibrary.wiley.com/doi/full/10.1002/app.30159 (accessed December 10, 2019).

[8] L. Mao, Y. Liu, H. Wu, J. Chen, J. Yao, Poly( $\varepsilon$-caprolactone) filled with polydopaminecoated high aspect ratio layered double hydroxide: Simultaneous enhancement of mechanical and barrier properties, Applied Clay Science. 150 (2017) 202-209.

https://doi.org/10.1016/j.clay.2017.09.031.

[9] F. Cavani, F. Trifirò, A. Vaccari, Hydrotalcite-type anionic clays: Preparation, properties and applications., Catalysis Today. 11 (1991) 173-301. https://doi.org/10.1016/09205861(91)80068-K.

[10] Antacid talcid activates in gastric mucosa genes encoding for EGF and its receptor. The molecular basis for its ulcer healing action. - Abstract - Europe PMC, (n.d.). http://europepmc.org/article/med/10791688 (accessed December 10, 2019).

[11] S.-J. Choi, J.-M. Oh, J.-H. Choy, Biocompatible ceramic nanocarrier for drug delivery with high efficiency, J. Ceram. Soc. Japan. 117 (2009) 543-549.

https://doi.org/10.2109/jcersj2.117.543. 
[12] V.R.R. Cunha, V.A. Guilherme, E. de Paula, D.R. de Araujo, R.O. Silva, J.V.R. Medeiros, J.R.S.A. Leite, P.A.D. Petersen, M. Foldvari, H.M. Petrilli, V.R.L. Constantino, Delivery system for mefenamic acid based on the nanocarrier layered double hydroxide: Physicochemical characterization and evaluation of anti-inflammatory and antinociceptive potential, Materials Science and Engineering: C. 58 (2016) 629-638. https://doi.org/10.1016/j.msec.2015.08.037.

[13] Y. Kuthati, R.K. Kankala, C.-H. Lee, Layered double hydroxide nanoparticles for biomedical applications: Current status and recent prospects, Applied Clay Science. 112-113 (2015) 100-116. https://doi.org/10.1016/j.clay.2015.04.018.

[14] M. Yan, C. Yang, B. Huang, Z. Huang, L. Huang, X. Zhang, C. Zhao, Systemic toxicity induced by aggregated layered double hydroxide nanoparticles, International Journal of Nanomedicine. (2017). https://doi.org/10.2147/IJN.S146414.

[15] Y.-M. Kuo, Y. Kuthati, R.K. Kankala, P.-R. Wei, C.-F. Weng, C.-L. Liu, P.-J. Sung, C.-Y. Mou, C.-H. Lee, Layered double hydroxide nanoparticles to enhance organ-specific targeting and the anti-proliferative effect of cisplatin, J. Mater. Chem. B. 3 (2015) 3447-3458. https://doi.org/10.1039/C4TB01989J.

[16] V.R.R. Cunha, R.B. de Souza, A.M.C.R.P. da Fonseca Martins, I.H.J. Koh, V.R.L. Constantino, Accessing the biocompatibility of layered double hydroxide by intramuscular implantation: histological and microcirculation evaluation, Sci Rep. 6 (2016) 30547. https://doi.org/10.1038/srep30547.

[17] M.P. Figueiredo, V.R.R. Cunha, F. Leroux, C.T. Gueho, M.N. Nakamae, Y.R. Kang, R.B. Souza, A.M.C.R.P.F. Martins, I.H.J. Koh, V.R.L. Constantino, Iron-based layered double hydroxide implants: potential drug delivery carriers with tissue biointegration promotion and blood microcirculation preservation, Acs Omega. 3 (2018) 18263-18274.

[18] Z. Gu, J.J. Atherton, Z.P. Xu, Hierarchical layered double hydroxide nanocomposites: structure, synthesis and applications, Chem. Commun. 51 (2015) 3024-3036. https://doi.org/10.1039/C4CC07715F.

[19] S.-J. Choi, J.-H. Choy, Layered double hydroxide nanoparticles as target-specific delivery carriers: uptake mechanism and toxicity, Nanomedicine (Lond). 6 (2011) 803-814. https://doi.org/10.2217/nnm.11.86.

[20] J.-M. Oh, S.-J. Choi, S.-T. Kim, J.-H. Choy, Cellular Uptake Mechanism of an Inorganic Nanovehicle and Its Drug Conjugates: Enhanced Efficacy Due To Clathrin-Mediated Endocytosis, Bioconjugate Chem. 17 (2006) 1411-1417. https://doi.org/10.1021/bc0601323.

[21] H. Nakayama, N. Wada, M. Tsuhako, Intercalation of amino acids and peptides into Mg-Al layered double hydroxide by reconstruction method, Int J Pharm. 269 (2004) 469-478. https://doi.org/10.1016/j.ijpharm.2003.09.043.

[22] V. Rives, M. del Arco, C. Martín, Layered double hydroxides as drug carriers and for controlled release of non-steroidal antiinflammatory drugs (NSAIDs): A review, Journal of Controlled Release. 169 (2013) 28-39. https://doi.org/10.1016/j.jconrel.2013.03.034. 
[23] L. Li, W. Gu, J. Chen, W. Chen, Z.P. Xu, Co-delivery of siRNAs and anti-cancer drugs using layered double hydroxide nanoparticles, Biomaterials. 35 (2014) 3331-3339. https://doi.org/10.1016/j.biomaterials.2013.12.095.

[24] G. Kapusetti, N. Misra, V. Singh, R.K. Kushwaha, P. Maiti, Bone cement/layered double hydroxide nanocomposites as potential biomaterials for joint implant: Bone Cement and LDH Nanocomposite, J. Biomed. Mater. Res. 100A (2012) 3363-3373.

https://doi.org/10.1002/jbm.a.34296.

[25] F. Fayyazbakhsh, M. Solati-Hashjin, A. Keshtkar, M.A. Shokrgozar, M.M. Dehghan, B. Larijani, Novel layered double hydroxides-hydroxyapatite/gelatin bone tissue engineering scaffolds: Fabrication, characterization, and in vivo study, Materials Science and Engineering: C. 76 (2017) 701-714. https://doi.org/10.1016/j.msec.2017.02.172.

[26] H. Kang, M. Kim, Q. Feng, S. Lin, K. Wei, R. Li, C.J. Choi, T.-H. Kim, G. Li, J.-M. Oh, L. Bian, Nanolayered hybrid mediates synergistic co-delivery of ligand and ligation activator for inducing stem cell differentiation and tissue healing, Biomaterials. 149 (2017) 12-28. https://doi.org/10.1016/j.biomaterials.2017.09.035.

[27] E. Valarezo, L. Tammaro, S. González, O. Malagón, V. Vittoria, Fabrication and sustained release properties of poly( $\varepsilon$-caprolactone) electrospun fibers loaded with layered double hydroxide nanoparticles intercalated with amoxicillin, Applied Clay Science. 72 (2013) 104-109. https://doi.org/10.1016/j.clay.2012.12.006.

[28] C. Yang, T. Zhu, J. Wang, S. Chen, W. Li, Synthesis and characterization of flurbiprofen axetil-loaded electrospun MgAl-LDHs/poly(lactic-co-glycolic acid) composite nanofibers, RSC Adv. 5 (2015) 69423-69429. https://doi.org/10.1039/C5RA11150A.

[29] L. Tammaro, G. Russo, V. Vittoria, Encapsulation of Diclofenac Molecules into Poly(Caprolactone) Electrospun Fibers for Delivery Protection, Journal of Nanomaterials. 2009 (2009) 1-8. https://doi.org/10.1155/2009/238206.

[30] Y. Gao, T.W. Teoh, Q. Wang, G.R. Williams, Electrospun organic-inorganic nanohybrids as sustained release drug delivery systems, J. Mater. Chem. B. 5 (2017) 9165-9174. https://doi.org/10.1039/C7TB01825H.

[31] Y.-E. Miao, H. Zhu, D. Chen, R. Wang, W.W. Tjiu, T. Liu, Electrospun fibers of layered double hydroxide/biopolymer nanocomposites as effective drug delivery systems, Materials Chemistry and Physics. 134 (2012) 623-630. https://doi.org/10.1016/j.matchemphys.2012.03.041.

[32] P. Raskin, R.A. Guthrie, L. Leiter, A. Riis, L. Jovanovic, Use of insulin aspart, a fast-acting insulin analog, as the mealtime insulin in the management of patients with type 1 diabetes., Diabetes Care. 23 (2000) 583-588. https://doi.org/10.2337/diacare.23.5.583.

[33] C. Morello, Pharmacokinetics and pharmacodynamics of insulin analogs in special populations with type 2 diabetes mellitus., International Journal of General Medicine. 4 (2011) 827-835. https://doi.org/10.2147/IJGM.S26889. 
[34] S. Christensen, E. Paluch, S. Jayawardena, S. Daniels, S. Meeves, Analgesic Efficacy of a New Immediate-Release/Extended-Release Formulation of Ibuprofen: Results From Single- and Multiple-Dose Postsurgical Dental Pain Studies, Clinical Pharmacology in Drug Development. 6 (2017) 302-312. https://doi.org/10.1002/cpdd.297.

[35] F.G. Eliaschewitz, T. Barreto, Concepts and clinical use of ultra-long basal insulin, Diabetology \& Metabolic Syndrome. 8 (2016) 2. https://doi.org/10.1186/s13098-015-0117-1.

[36] P. Gao, X. Nie, M. Zou, Y. Shi, G. Cheng, Recent advances in materials for extendedrelease antibiotic delivery system, The Journal of Antibiotics. 64 (2011) 625-634. https://doi.org/10.1038/ja.2011.58.

[37] C.F. Weiniger, M. Golovanevski, M. Sokolsky-Papkov, A. Domb, Review of prolonged local anesthetic action, Expert Opinion on Drug Delivery. 7 (2010) 737-752. https://doi.org/10.1517/17425241003767383.

[38] S.K. Boda, X. Li, J. Xie, Electrospraying an enabling technology for pharmaceutical and biomedical applications: A review, J Aerosol Sci. 125 (2018) 164-181. https://doi.org/10.1016/j.jaerosci.2018.04.002.

[39] S. Nedjari, A. Hébraud, S. Eap, S. Siegwald, C. Mélart, N. Benkirane-Jessel, G. Schlatter, Electrostatic template-assisted deposition of microparticles on electrospun nanofibers: towards microstructured functional biochips for screening applications, RSC Advances. 5 (2015) 83600-83607. https://doi.org/10.1039/C5RA15931H.

[40] C.R. Wittmer, A. Hébraud, S. Nedjari, G. Schlatter, Well-organized 3D nanofibrous composite constructs using cooperative effects between electrospinning and electrospraying, Polymer. 55 (2014) 5781-5787. https://doi.org/10.1016/j.polymer.2014.08.044.

[41] A. Garcia Garcia, A. Hébraud, J.-L. Duval, C.R. Wittmer, L. Gaut, D. Duprez, C. Egles, F. Bedoui, G. Schlatter, C. Legallais, Poly( $\varepsilon$-caprolactone)/Hydroxyapatite 3D Honeycomb Scaffolds for a Cellular Microenvironment Adapted to Maxillofacial Bone Reconstruction, ACS Biomater. Sci. Eng. 4 (2018) 3317-3326. https://doi.org/10.1021/acsbiomaterials.8b00521.

[42] N. Lavielle, A. Hébraud, L. Thöny-Meyer, R.M. Rossi, G. Schlatter, 3D Composite Assemblies of Microparticles and Nanofibers for Tailored Wettability and Controlled Drug Delivery, Macromol. Mater. Eng. 302 (2017) 1600458. https://doi.org/10.1002/mame.201600458.

[43] M. Mold, E. Shardlow, C. Exley, Insight into the cellular fate and toxicity of aluminium adjuvants used in clinically approved human vaccinations, Sci Rep. 6 (2016) 31578. https://doi.org/10.1038/srep31578.

[44] D. Krewski, R.A. Yokel, E. Nieboer, D. Borchelt, J. Cohen, J. Harry, S. Kacew, J. Lindsay, A.M. Mahfouz, V. Rondeau, Human health risk assessment for aluminium, aluminium oxide, and aluminium hydroxide, J Toxicol Environ Health B Crit Rev. 10 Suppl 1 (2007) 1-269. https://doi.org/10.1080/10937400701597766. 
[45] V. Kumar, K. Gill, Aluminium neurotoxicity: Neurobehavioural and oxidative aspects, Archives of Toxicology. 83 (2009) 965-978. https://doi.org/10.1007/s00204-009-0455-6.

[46] M. Delarco, A. Fernandez, C. Martin, V. Rives, Release studies of different NSAIDs encapsulated in Mg,Al,Fe-hydrotalcites, Applied Clay Science. 42 (2009) 538-544.

https://doi.org/10.1016/j.clay.2008.06.014.

[47] M. del Arco, S. Gutiérrez, C. Martín, V. Rives, J. Rocha, Synthesis and characterization of layered double hydroxides (LDH) intercalated with non-steroidal anti-inflammatory drugs (NSAID), Journal of Solid State Chemistry. 177 (2004) 3954-3962.

https://doi.org/10.1016/j.jssc.2004.08.006.

[48] M. Wei, S. Shi, J. Wang, Y. Li, X. Duan, Studies on the intercalation of naproxen into layered double hydroxide and its thermal decomposition by in situ FT-IR and in situ HT-XRD, Journal of Solid State Chemistry. 177 (2004) 2534-2541.

https://doi.org/10.1016/j.jssc.2004.03.041.

[49] D.L.A. de Faria, V.R.L. Constantino, K.J. Baldwin, D.N. Batchelder, T.J. Pinnavaia, M. Chibwe, Raman microspectroscopy of phthalocyanine intercalates: tetrasulphonated cobalt and nickel phthalocyanines in layered double hydroxide, Journal of Raman Spectroscopy. 29 (1998) 103-108. https://doi.org/10.1002/(SICI)1097-4555(199802)29:2<103::AIDJRS199>3.0.CO;2-J.

[50] Y. Cai, J. Lv, J. Feng, Spectral Characterization of Four Kinds of Biodegradable Plastics: Poly (Lactic Acid), Poly (Butylenes Adipate-Co-Terephthalate), Poly (Hydroxybutyrate-CoHydroxyvalerate) and Poly (Butylenes Succinate) with FTIR and Raman Spectroscopy, J Polym Environ. 21 (2013) 108-114. https://doi.org/10.1007/s10924-012-0534-2.

[51] P.L. Ritger, N.A. Peppas, A simple equation for description of solute release I. Fickian and non-fickian release from non-swellable devices in the form of slabs, spheres, cylinders or discs, Journal of Controlled Release. 5 (1987) 23-36. https://doi.org/10.1016/01683659(87)90034-4.

[52] H.J. Haroosh, Y. Dong, G.D. Ingram, Synthesis, morphological structures, and material characterization of electrospun PLA:PCL/magnetic nanoparticle composites for drug delivery, Journal of Polymer Science, Part B: Polymer Physics. 51 (2013) 1607-1617.

https://doi.org/10.1002/polb.23374.

[53] A. Fahami, M. Fathi, Development of cress seed mucilage/PVA nanofibers as a novel carrier for vitamin A delivery, Food Hydrocolloids. 81 (2018) 31-38.

https://doi.org/10.1016/j.foodhyd.2018.02.008.

[54] M. Chakraborty, S. Dasgupta, S. Sengupta, J. Chakraborty, S. Ghosh, J. Ghosh, M.K. Mitra, A. Mishra, T.K. Mandal, D. Basu, A facile synthetic strategy for Mg-Al layered double hydroxide material as nanocarrier for methotrexate, Ceramics International. 38 (2012) 941949. https://doi.org/10.1016/j.ceramint.2011.08.014. 
[55] X.-Q. Zhang, M.-G. Zeng, S.-P. Li, X.-D. Li, Methotrexate intercalated layered double hydroxides with different particle sizes: Structural study and Controlled release properties, Colloids and Surfaces B: Biointerfaces. 117 (2014) 98-106.

https://doi.org/10.1016/j.colsurfb.2014.02.018.

[56] D.L. Sparks, Kinetics and Mechanisms of Chemical Reactions at the Soil Mineral/Water Interface, Soil Physical Chemistry. (2018). https://doi.org/10.1201/9780203739280-4.

[57] T. O'Hara, A. Dunne, J. Butler, J. Devane, A review of methods used to compare dissolution profile data, Pharmaceutical Science \& Technology Today. 1 (1998) 214-223. https://doi.org/10.1016/S1461-5347(98)00053-4. 